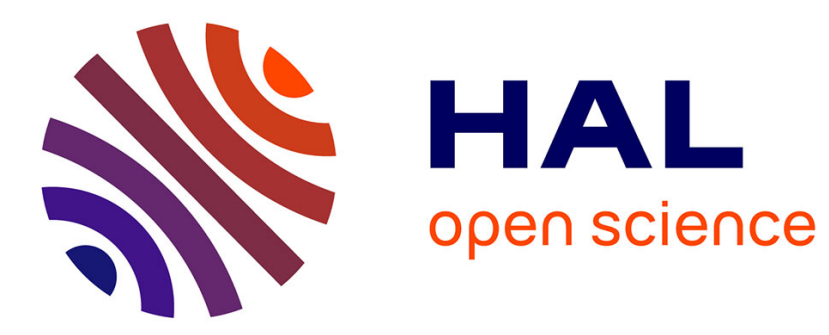

\title{
Can Wages Signal Kindness?
}

Emrah Arbak, Laurence Kranich

\section{To cite this version:}

Emrah Arbak, Laurence Kranich. Can Wages Signal Kindness?. 2005. halshs-00180032

\section{HAL Id: halshs-00180032 \\ https://shs.hal.science/halshs-00180032}

Submitted on 17 Oct 2007

HAL is a multi-disciplinary open access archive for the deposit and dissemination of scientific research documents, whether they are published or not. The documents may come from teaching and research institutions in France or abroad, or from public or private research centers.
L'archive ouverte pluridisciplinaire HAL, est destinée au dépôt et à la diffusion de documents scientifiques de niveau recherche, publiés ou non, émanant des établissements d'enseignement et de recherche français ou étrangers, des laboratoires publics ou privés. 


\title{
Can Wages Signal Kindness?
}

\author{
Emrah Arbak , Laurence Kranich
}

Novembre 2005

GATE Groupe d'Analyse et de Théorie Économique UMR 5824 du CNRS

93 chemin des Mouilles - 69130 Écully - France

B.P. $167-69131$ Écully Cedex

Tél. +33 (0)4 72866060 - Fax +33 (0)4 72866090

Messagerie électronique gate@gate.cnrs.fr Serveur Web : www.gate.cnrs.fr 


\title{
Can Wages Signal Kindness?
}

\author{
Emrah Arbak* and Laurence Kranich ${ }^{\dagger}$
}

November 4, 2005

\begin{abstract}
We model the interaction between an employer and a worker with interdependent preferences in a simple one-shot production process. In particular, we assume that the worker becomes kinder if she senses that her employer is an altruist. We assume that intentions are private information. Thus, the wage proposal signals the intentions of the employer to the worker. We show that if the workers have "reasonable" beliefs, then the unique prediction of the game is a separating equilibrium outcome in which wages are fully informative about the intentions of the employer. However, if there are several employers simultaneously bidding to hire a single worker, then there may exist another equilibrium in which wages are completely uninformative.
\end{abstract}

JEL Classification: C72, D82, J30

Keywords: Altruism, reciprocity, asymmetric information, labor relations, behavioral game theory.

\footnotetext{
*GATE - Groupe d'Analyse et de Théorie Economique (CNRS, Université Lyon 2, Ecole Normale Supérieure LSH), 93, chemin des Mouilles 69130 Ecully, France. E-mail : arbak@gate.cnrs.fr

${ }^{\dagger}$ Department of Economics, University at Albany, SUNY. Mailing address: 1400 Washington Ave., Albany, NY 12222, USA. E-mail: L.Kranich@albany.edu
} 


\section{Introduction}

It is quite clear that at least some of our daily interactions are influenced by motives other than pure self-interest. While such a statement would face little or no scrutiny in many disciplines, economists have systematically overlooked these motives in the past. After all, for an economist who depicts an economic agent as a rational and self-indulgent decision maker, all behavior must eventually lead to some private gain. For example, if you give someone a gift, the only explanation based on egocentric rationality is that you expect that your gift will induce a favorable response from the other person and will ultimately yield a positive net private gain. Recent experimental evidence, however, displays many instances in which economic actors seem to be motivated by more than just their selfish needs. People contribute more than expected in experiments using simple games such as ultimatum, dictator, gift-exchange, and public good games.

How does one come to care for another? Are we born to like some people and dislike others, or are our extended preferences context-dependent, arising only when a set of specific conditions are met? Recent experimental research indicates that individuals seem to have a propensity to reward generous behavior and punish unkind behavior. ${ }^{1}$ The dependence of one's own motives upon the motives of another is commonly observed in our daily interactions. Individuals constantly consider certain actions as signs of respect, care, etc. These considerations are the crucial fabric of the emotional arithmetic of a decision maker.

In this paper, we restrict our attention to a simple model of the labor market where an employer offers a wage schedule to a single worker. The wage is designed not only to provide the proper incentives to work hard, but also to signal the employer's motives. If the worker believes that an employer is being genuinely kind, he develops an affinity for the employer and thus responds kindly by working hard or not changing his job as soon as another employer offers him a better wage. Otherwise, if the employer's behavior is interpreted as being motivated by selfishness, the worker will respond as her selfish needs guide her. We call our model a loyalty model, since we consider the reciprocal actions of a worker based on the (partial) observation of the employer's motives. In other words, a worker is loyal only if the employer has kind motives. However, this does not mean that a selfish employer never gets some form of loyalty. According to our model, a

\footnotetext{
${ }^{1}$ Ledyard [13] provides a review of public good experiments; Güth [12] and Roth [17] summarizes experimental evidence regarding ultimatum games. See Camerer [5] for a general review of the subject.
} 
selfish employer indeed pays for loyalty at a pooling equilibrium. At a separating equilibrium, however, being selfish ensures that the workers will not be loyal or kind in return.

One may wonder whether the information regarding an employer's motives is a factor in labor relations. A recent international survey of human resource managers by Manpower Inc. reports that the managers rated "keeping an open and honest communication" as one of their top "loyalty drivers." The motives of an employer can be a motivation for workers by way of loyalty. The motives of an employer, however, are not always observable. In such instances, an employer may be able to signal her motives by providing pecuniary and non-pecuniary incentives. In this paper, we allow employers to offer only pecuniary benefits to their workers. ${ }^{2}$ In this perspective, the interactions between an employer and a worker may be interpreted as a gift-exchange.

The first model to view labor relations as a partial gift exchange is Akerlof's [1] seminal article. According to Akerlof [1], a fair wage generates a positive feeling to drive the employees to exert more effort than a required minimum. In our model wages do generate similar emotions, however, their ability to do so varies with the economic environment. Moreover, our model does not consider fairness or other forms of inequity concerns as a basis to explain behavior. This choice is not motivated by a dismissal of the results obtained by utilizing notions of fairness or equity. ${ }^{3}$ We do not allow fairness considerations to retain the simplicity of the model.

Our model is quite similar to the approaches of Rabin [16] and Levine [14], where individuals may choose to sacrifice their own welfare to help/punish those that have been kind/unkind. ${ }^{4}$ Much like Levine's [14] model, we do not consider

\footnotetext{
${ }^{2}$ The success of pecuniary benefits to enhance loyalty has been questioned by some researchers. However, there is also a growing realisation among human resource managers and other professionals that wages and bonuses do serve as important tools in shaping loyalty. A recent document, obtained from the website of a private consulting firm, headlined "How to Create Employee Loyalty", argues that pay and benefits help retain the most devoted workers. Also, telephone interviews conducted by Beta Research Corporation find that a quarter of the hiring managers polled rate raises and bonuses as the most effective programs that enhance employee loyalty/retention; for article see Business Wire, May 7, 2003, p.2198.

${ }^{3}$ For more on inequity aversion as the basis for kindness, see Bolton and Ockenfels [3] and Fehr and Schmidt [10].

${ }^{4}$ There is a fast growing literature that analyzes the consequences of reciprocal behavior and related phenomenon. Our model is similar to Falk and Fischbacher's [8] model of reciprocity, although we consider a signalling game while the authors use a psychological game approach. See Fehr and Gächter [9], Sethi and Somanathan [18], and Sobel [19] for revisions.
} 
a "psychological game" in which agents payoffs may depend directly on beliefs as well as actions. ${ }^{5}$ Instead, we allow a worker's altruism coefficient to be dependent on the altruism coefficient of an employer. Unlike Levine's [14] model, however, we do not allow the agents to be spiteful and focus on selfish and kind motives. Moreover, we are interested in a stylized labor market interaction, whereas Levine [14] considers simple game forms. ${ }^{6}$

The results of our model show that employers can indeed signal their intentions in some cases. In particular, we find that by imposing a relatively weak restriction on the beliefs of workers, there exists a unique separating equilibrium. However, we find that signalling possibilities are significantly reduced if several employers compete to hire a single worker or if appearing to be selfish reduces an employer's ability to attract workers. These results seem to lend support to some of the experimental findings of Charness and Haruvy [6] which shows that allowing wages to be determined by an external process reduces an agent's willingness to reciprocate. Our results also resembles the findings of Prasnikar and Roth [15] who report that increasing the number of proposers in an ultimatum game experiment produces outcomes that are similar to the standard predictions of game theory.

\section{Simple model}

Consider a sequential interaction in which an employer wishes to hire a worker for a one-time project with an uncertain outcome, $y$. To simplify matters, suppose that the project yields either no output or a single unit of output, $y=0,1$. The outcome of the project is dependent on the worker's effort $0 \leq e \leq 1$, which also equals the project's probability of success. The expected output of the project is simply $e \cdot 1+(1-e) \cdot 0=e$. Throughout the paper, we maintain that the worker's effort is private information.

The task of the employer is to devise a compensation scheme that provides the necessary incentives to work. In the first stage, the employer proposes a payment schedule, wy, dependent, at least partially, on the outcome of the project, with $0 \leq w \leq 1 .^{7}$ In the second stage, the worker either accepts the employer's offer

\footnotetext{
${ }^{5}$ See the seminal article of Geanakoplos, Pearce, and Stacchetti [11] on psychological games.

${ }^{6}$ See also Bernheim and Severinov [2] for a signaling game similar to ours.

${ }^{7} \mathrm{An}$ implicit assumption here is that the employer is liquidity constrained, such that she can only consider a payment schedule dependent on the outcome of the project. See the Appendix for an extension of our results in this section by allowing the employer to diversify her risks by
} 
$w$ and chooses to devote some effort $e$ - with the understanding that she will be paid in the event that the project is a success - or rejects the offer altogether to obtain her default utility, $\underline{u}=0$.

Let the opportunity cost of the project be equivalent to the production unit's sale value, denoted by the constant $r>0$. The employer needs to pay this opportunity cost to the actual owners of the production unit. Alternatively, $r$ may be interpreted as the cost of capital, or the rent paid to the owners of the stock of capital. Let $r$ be given exogenously.

We assume that both the employer and the worker are risk-neutral. Then, the expected profit of an employer is

$$
\pi(w, e \mid r)=(1-w) e-r .
$$

Similarly, the expected private utility of a worker is given by

$$
u(w, e)=w e-g(e)
$$

where $g:[0,1] \rightarrow \mathcal{R}_{+}$signifies the worker's cost of effort. We assume that $g$ is $\mathcal{C}^{3}$, $g(0)=0, g^{\prime}, g^{\prime \prime}>0$ on $(0,1]$, and $g^{\prime \prime \prime} \geq 0$. Lastly, let us assume that $g$ satisfies the Inada condition $g^{\prime}(0)=0$ and $g^{\prime}(1)>1$, which are sufficient to ensure interior solutions for the worker's effort decision.

Apart from their selfish interests, an employer and a worker may also care about each other's welfare. We first consider the employer's extended preferences. Imagine that the motive of an employer is exogenously given and determined by a random move of nature. The extended (expected) payoff of a type $i$ employer is then given by

$$
V_{i}(w, e \mid r)=\pi(w, e \mid r)+\alpha_{i} u(w, e) .
$$

Suppose that there are two types of employers, $i=K, M$ with $\alpha_{K}>\alpha_{M}=0$, such that type $M$ employers are solely profit maximizing and type $K$ employers are kind, or benevolent. Let $p_{i}$ denote the probability that nature picks a type $i$ employer.

While an employer may be innately kind, a worker cares for the employer in a reciprocal manner - only if she believes that the employer also cares for her. Then, the employer's compensation scheme may provide the worker hints regarding her underlying motives. Unlike other models of reciprocity, a "good" offer does not

employing a large number of workers, which allows the employer to also include a fixed payment component. 
automatically trigger a reciprocal response from the worker. After all, the worker knows that a materialist employer may be interested in being recognized as a caring employer by making an offer that makes the worker uncertain, if doing so yields the employer greater profits. Therefore, the worker responds reciprocally only if she has reason to believe that the employer's offer is genuine and reflects her underlying kindness.

Let $\mu_{i} \in[0,1]$ be the worker's belief about the employer's type, such that $\mu_{i}=1$ if the worker believes that the employer has type $i$ motives. Also, let $\mu=\left(\mu_{K}, \mu_{M}\right)$ denote the vector of beliefs. The worker's extended (expected) payoff is

$$
U(w, e, b \mid r)=u(w, e)+b \cdot \pi(w, e \mid r)
$$

where the worker's care about the employer's profit is simply

$$
b=\beta \cdot \mu_{K} \cdot \alpha_{K} .
$$

In the previous equation, $\mu_{K} \alpha_{K}$ represents the worker's anticipation of the employer's altruism coefficient and $\beta \in[0,1]$ determines the extent to which the worker cares for the employer's motives. Since the worker's objective function $U$ is strictly concave in $e$, her best response to wage $w$ is uniquely identified. Let

$$
\mathcal{E}(w, b)=\arg \max _{e \in[0,1]} U(w, e, b \mid r)
$$

denote the worker's best response function.

A worker agrees to work only if the employer's offer yields a sufficiently large private payoff, or only if $u \geq 0 .{ }^{8}$ If there is more than a single employer, then the worker may compare the employers' offers by considering their implied extended payoffs. We consider such extensions in the following sections. In this section, we focus solely on an interaction between an employer and a worker.

It is easy to show that a positive wage will make the worker better-off than her default utility if the worker knows with certainty that the employer is type $M$, or that

$$
\max _{e \in[0,1]} u(w, e) \geq 0,
$$

for all $w \geq 0$, holding with equality only when $w=0$.

Since the employer is liquidity-constrained, she chooses to implement the project only if $\pi \geq 0$. Otherwise, the employer will choose not to implement

\footnotetext{
${ }^{8}$ We may justify this restriction by interpreting a negative private utility as a below substinance payoff associated with inferior health status, being homeless, etc.
} 
the project and will earn her reservation profit of zero. Let us assume that for some wage the project yields strictly positive profits even if the worker believes that the employer is materialist, or that

$$
\pi(w, \mathcal{E}(w, 0) \mid r)>0
$$

for some $w \geq 0 .^{9}$

We have not yet pinned down the information structure of our model. The assumption that the worker's effort is not observable by the employer is maintained throughout the paper. There is another potential form of information imperfection in our model: The employer's motives may not be revealed to the worker. In that case, the wage offer not only provides incentives but may also be informative about the employer's motive. Before discussing the resulting signalling model in detail, in the next subsection we briefly consider the implications of our model when the employer's type is public information.

\subsection{Observed Motives}

When the employer's motives are observable, then a type $i=K, M$ employer's decision in the first stage can be specified as follows:

$$
\max _{w \in[0,1]} V_{i}\left(w, \mathcal{E}\left(w, b_{i}\right) \mid r\right) \text { s.t. } u\left(w, \mathcal{E}\left(w, b_{i}\right)\right) \geq 0
$$

with $b_{i}=\beta \cdot \alpha_{i}$.

The next lemma summarizes some important properties of the best-response function $\mathcal{E}$ when the worker's care for the employer, $b_{i}$, is exogenously determined.

Lemma 2.1. $\mathcal{E}(\cdot, \cdot)$ is strictly increasing in both its arguments and concave in $w$. Also, $V_{i}\left(w, \mathcal{E}\left(w, b_{i}\right) \mid r\right)$ is concave in $w$.

Proof. Let $w_{1}, w_{2} \in[0,1]$ with $w_{2} \neq w_{1}$ and $w_{\gamma}=\gamma w_{1}+(1-\gamma) w_{2}$ for some $\gamma \in[0,1]$. Also, in order to ease notation, let $\mathcal{E}_{x}=\mathcal{E}\left(w_{x}, b\right)$. We write the firstorder condition corresponding to the optimization problem given in equation (2.5) as

$$
w(1-b)+b-g^{\prime}\left(e^{*}\right)=0,
$$

\footnotetext{
${ }^{9}$ In order to prove that such a wage exists, it is sufficient to show that the worker exerts a strictly positive amount of effort when $b=0$. To see this, note that our assumption regarding $g^{\prime}$ ensures that first order derivative of the worker's objective function $u$ is strictly positive for $e=0$ and $w>0$, i.e. $w-g^{\prime}(0)>0$ for any $w>0$.
} 
where $e^{*}=\mathcal{E}(w, b)$. Then,

$$
\begin{aligned}
0 & =\gamma\left(w_{1}(1-b)+b-g^{\prime}\left(\mathcal{E}_{1}\right)\right)+(1-\gamma)\left(w_{2}(1-b)+b-g^{\prime}\left(\mathcal{E}_{2}\right)\right) \\
& =w_{\gamma}(1-b)+b-\gamma g^{\prime}\left(\mathcal{E}_{1}\right)-(1-\gamma) g^{\prime}\left(\mathcal{E}_{2}\right)
\end{aligned}
$$

Since $g^{\prime}$ is convex, we have $g^{\prime}\left(\gamma \mathcal{E}_{1}+(1-\gamma) \mathcal{E}_{2}\right) \leq \gamma g^{\prime}\left(\mathcal{E}_{1}\right)+(1-\gamma) g^{\prime}\left(\mathcal{E}_{2}\right)$. Substituting this inequality into the previous equation, we get

$$
\begin{aligned}
0 & =w_{\gamma}(1-b)+b-\gamma g^{\prime}\left(\mathcal{E}_{1}\right)-(1-\gamma) g^{\prime}\left(\mathcal{E}_{2}\right) \\
& \leq w_{\gamma}(1-b)+b-g^{\prime}\left(\gamma \mathcal{E}_{1}+(1-\gamma) \mathcal{E}_{2}\right)
\end{aligned}
$$

But this means that the worker should respond to wage $w_{\gamma}$ by working no less than $\gamma \mathcal{E}_{1}+(1-\gamma) \mathcal{E}_{2}$, or by setting $\mathcal{E}_{\gamma} \geq \gamma \mathcal{E}_{1}+(1-\gamma) \mathcal{E}_{2}$.

To show that $V_{i}$ is concave in $w$, we first write

$$
\begin{aligned}
V_{i}\left(w_{\gamma}, \mathcal{E}_{\gamma} \mid r\right) & =\left(1-w_{\gamma}\right) \mathcal{E}_{\gamma}+\alpha_{i}\left(w_{\gamma} \mathcal{E}_{\gamma}-g\left(\mathcal{E}_{\gamma}\right)\right)-r \\
& =\left(1-w_{\gamma}\left(1-\alpha_{i}\right)\right) \mathcal{E}_{\gamma}-\alpha_{i} g\left(\mathcal{E}_{\gamma}\right)-r
\end{aligned}
$$

Now, we know from above that $\mathcal{E}_{\gamma} \geq \gamma \mathcal{E}_{1}+(1-\gamma) \mathcal{E}_{2}$, and since $-g(\cdot)$ is (strictly) concave, by definition, $-g\left(\mathcal{E}_{\gamma}\right)$ is concave in $w$. Then,

$$
\begin{aligned}
V_{i}\left(w_{\gamma}, \mathcal{E}_{\gamma} \mid r\right) \geq & \gamma \mathcal{E}_{1}+(1-\gamma) \mathcal{E}_{2} \\
& -\left(1-\alpha_{i}\right)\left(\gamma w_{1}+(1-\gamma) w_{2}\right)\left(\gamma \mathcal{E}_{1}+(1-\gamma) \mathcal{E}_{2}\right) \\
& -\alpha_{i}\left(\gamma g\left(\mathcal{E}_{1}\right)+(1-\gamma) g\left(\mathcal{E}_{2}\right)\right)-r \\
= & \gamma \mathcal{E}_{1}+(1-\gamma) \mathcal{E}_{2} \\
& -\left(1-\alpha_{i}\right)\left(\gamma w_{1} \mathcal{E}_{1}+(1-\gamma) w_{2} \mathcal{E}_{2}-\gamma(1-\gamma)\left(w_{1}-w_{2}\right)\left(\mathcal{E}_{1}-\mathcal{E}_{2}\right)\right) \\
& -\alpha_{i}\left(\gamma g\left(\mathcal{E}_{1}\right)+(1-\gamma) g\left(\mathcal{E}_{2}\right)\right)-r
\end{aligned}
$$

Rearranging further, we have

$$
\begin{aligned}
V_{i}\left(w_{\gamma}, \mathcal{E}_{\gamma} \mid r\right) \geq & \gamma\left(1-w_{1}\left(1-\alpha_{i}\right)\right) \mathcal{E}_{1}+(1-\gamma)\left(1-w_{2}\left(1-\alpha_{i}\right)\right) \mathcal{E}_{2} \\
& +\gamma(1-\gamma)\left(1-\alpha_{i}\right)\left(w_{1}-w_{2}\right)\left(\mathcal{E}_{1}-\mathcal{E}_{2}\right) \\
& -\alpha_{i}\left(\gamma g\left(\mathcal{E}_{1}\right)+(1-\gamma) g\left(\mathcal{E}_{2}\right)\right)-r .
\end{aligned}
$$

Note that our previous findings show that $\left(w_{1}-w_{2}\right)\left(\mathcal{E}_{1}-\mathcal{E}_{2}\right) \geq 0$, which allows us to rearrange the previous term as

$$
\begin{aligned}
V_{i}\left(w_{\gamma}, \mathcal{E}_{\gamma} \mid r\right) \geq & \gamma\left(\left(1-w_{1}\left(1-\alpha_{i}\right)\right) \mathcal{E}_{1}-\alpha_{i} g\left(\mathcal{E}_{1}\right)-r\right) \\
& +(1-\gamma)\left(\left(1-w_{2}\left(1-\alpha_{i}\right)\right) \mathcal{E}_{2}-\alpha_{i} g\left(\mathcal{E}_{2}\right)-r\right) \\
= & \gamma V_{i}\left(w_{1}, \mathcal{E}_{1} \mid r\right)+(1-\gamma) V_{i}\left(w_{2}, \mathcal{E}_{2} \mid r\right) .
\end{aligned}
$$


Since the employer's motive is publicly observed, we may want to characterize the relationship between the employer's wage choice and the worker's reaction coefficient, $\beta$. As our previous result shows if $\beta$ is large, then the worker will work harder for any given wage. In other words, a reactive worker may need less than the usual incentives to work if the employer is benevolent, since the employer's welfare is integrated into the worker's objective. Then, it may be profitable for the employer to offer a relatively lower wage to a more reactionary worker. Our next result supports our intuition.

Corollary 2.2. The employer's wage offer $w$ is strictly decreasing in $\beta$.

Proof. The first order condition for the worker is

$$
\begin{aligned}
& \frac{\partial\left[w e-g(e)+\beta \alpha_{i}(1-w) e\right]}{\partial e} \\
= & w+\beta \alpha_{i}(1-w)-g^{\prime}(e) \\
= & 0 .
\end{aligned}
$$

Applying the Implicit Function Theorem to the worker's optimization, we get

$$
\begin{aligned}
\frac{\partial \mathcal{E}}{\partial w} & =\frac{1-\alpha_{i} \beta}{g^{\prime \prime}}>0, \\
\frac{\partial \mathcal{E}}{\partial \beta} & =\frac{\alpha_{i}(1-w)}{g^{\prime \prime}}>0 .
\end{aligned}
$$

Substituting the worker's optimal response rule, $g^{\prime}(e)=w+\beta \alpha_{i}(1-w)$, the first order condition for a type $i$ employer can be written as

$$
\begin{aligned}
& \frac{\partial\left[(1-w) \mathcal{E}+\alpha_{i}(w \mathcal{E}-g(\mathcal{E}))\right]}{\partial w} \\
= & \frac{\partial \mathcal{E}}{\partial w} \cdot\left(1-\left(1-\alpha_{i}\right) w-\alpha_{i} g^{\prime}(\mathcal{E})\right)-\left(1-\alpha_{i}\right) \mathcal{E} \\
= & \left(\left(\frac{1-\alpha_{i} \beta}{g^{\prime \prime}}\right) \cdot\left(1-\alpha_{i}^{2} \beta\right)(1-w)\right)-\left(1-\alpha_{i}\right) \mathcal{E}=0
\end{aligned}
$$

where $\mathcal{E}=\mathcal{E}\left(w, b_{i}\right)$. Our result follows since the function on the left side of the last equation decreases with $\beta$.

The next example illustrates the previous result. 


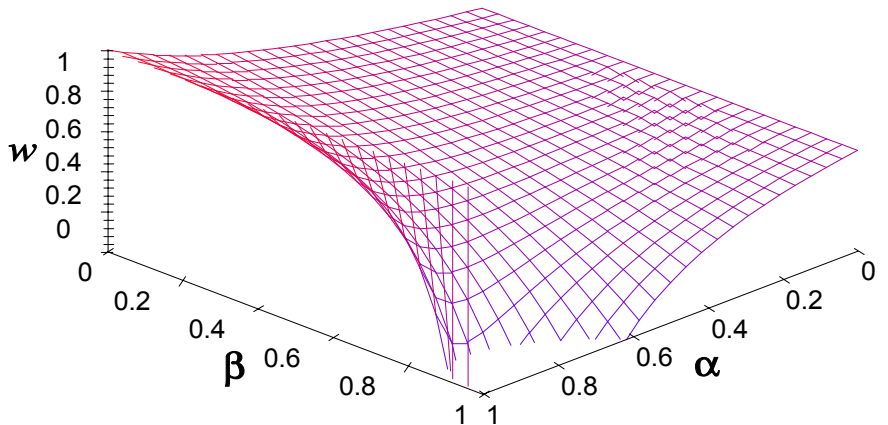

Figure 2.1: Wages when the employer's type is kind and observable.

Example 2.3. Let us assume that $g(e)=e^{2}$. If the employer is materialist then it can easily be shown that $e=\frac{1}{4}$ and $w=\frac{1}{2}$. If the employer is kind, then the worker's optimization yields the following best response function:

$$
\mathcal{E}(w, \alpha \beta)=\frac{1}{2}(w+\alpha \beta(1-w)) .
$$

The employer's optimization yields the wages as a function of the kindness of the employer, $\alpha$, and the responsiveness of the worker, $\beta$, as depicted in figure 2.1.

\subsection{Signaling with reasonable beliefs}

Suppose now that the employer's type is unobserved and that the worker has to draw inferences about the employer's motive from her offer. In other words, we now allow $\mu$ to be a function of $w$. Also, we consider only pure strategies. We next define our equilibrium concept.

Definition 2.4. A perfect Bayesian equilibrium (PBE) of the signaling game is a profile $\left(w_{i}^{*}, e^{*}(w), \mu_{i}^{*}(w)\right)_{i \in\{M, K\}}$ that satisfies the following conditions.

(P1) For all $w \in[0,1]$, the equilibrium effort levels are also optimal:

$$
e^{*}(w)=\mathcal{E}\left(w, \beta \mu_{K}^{*}(w) \alpha_{K}\right) .
$$

(P2) For all $i=M, K$, the equilibrium wage $w_{i}^{*}$ is optimal:

$$
V_{i}\left(w_{i}^{*}, e^{*}\left(w_{i}^{*}\right)\right) \geq V_{i}\left(w, e^{*}(w)\right)
$$


for any $w \in[0,1]$.

(B) For all $i=M, K$, the worker's beliefs obey Bayes' rule, whenever applicable:

$$
\mu_{i}^{*}(w)=\frac{p_{i} \sigma_{i}^{*}(w)}{\sum p_{j} \sigma_{j}^{*}(w)},
$$

where

$$
\sigma_{i}^{*}(w)= \begin{cases}1 & \text { if } w=w^{*}\left(\alpha_{i}\right) \\ 0 & \text { otherwise }\end{cases}
$$

and $\sum p_{i} \sigma_{i}^{*}(w)>0$.

A simple but important property of most signaling models is that the sender's, i.e. the employer's, indifference curves cross only once. A direct consequence of this property is that the receiver's actions are monotonic in the sender's messages. When such a simple relationship exists between the two choice variables, senders may be separated by their actions.

The single-crossing property is not necessarily satisfied here. To see this, note that the marginal payoff from effort may actually be negative for a type $K$ employer - since additional effort may be too costly for the worker - while it is always non-negative for a type $M$ employer. In other words, the preferences of a caring employer may exhibit a "bliss-point", above which any additional amount of effort actually subtracts from the extended welfare of the employer. This negative effect originates from the benevolence of the employer. While a bliss-point does not exist for a materialist employer, simply because increasing the worker's effort level never decreases the employer's profit, a kind employer also considers the marginal disutility of effort implied by any contract. For sufficiently high effort levels, the marginal value of effort may be negative for a type $K$ employer, and thus our model invites the possibility of multiple-crossing indifference curves, as shown in Figure 2.2.

Example 2.5. Let us, as before, assume that $g(e)=e^{2}, r=0$, and $\alpha=0.7$. Then, the indifference curves are determined by the equations

$$
\begin{aligned}
V_{K}(w, e) & =(1-w) e+0.7\left(w e-e^{2}\right)=C, \\
V_{M}(w, e) & =(1-w) e=C
\end{aligned}
$$

where $C$ is some constant. Figure 2.2 depicts the indifference curves for both types of agents when $C=0.2$. Note that the indifference curve of a kind employer 


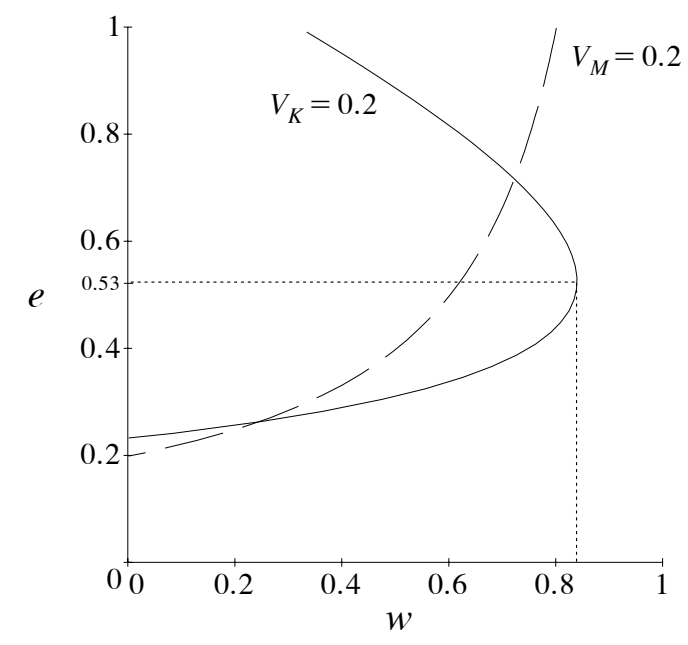

Figure 2.2: The indifference curves for both types of employers when $g(e)=e^{2}$ and $\alpha=0.7$.

has a bliss-point at $(w, e) \approx(0.84,0.53)$. Indeed, with these parameters, a kind employer's welfare diminishes in effort $e$, for any $e>0.53$, holding wage $w$ constant. The materialist employer's welfare, on the other hand, is always improved if the worker exerts more effort for any constant wage.

Fortunately, one can show that our model satisfies the single-crossing property for the range of choices that are of interest to us. We now define

$$
\varepsilon(w)=\bigcup_{\mu \in[0,1]} \mathcal{E}(w, \alpha \beta \mu)
$$

to designate the worker's set of best responses to $w$ corresponding to all possible beliefs. Note that with the parameters used in the previous example, the worker's choices are bounded from above, $\varepsilon(1) \leq 1 / 2<0.53$, as depicted on Figure 2.2.

Lemma 2.6. The employer's preferences satisfy the single-crossing property for all $w \in[0,1]$ and $e \in[0, \varepsilon(1)]$.

Proof. Note that for any $w \in[0,1], \varepsilon(w)$ can be alternatively described as

$$
\varepsilon(w)=\left\{e: \gamma-g^{\prime}(e)=0 \text { for all } \gamma \in\left[w, w+\beta \alpha_{K}(1-w)\right]\right\} .
$$


Then, $1=g^{\prime}(e)$ if $\{e\}=\varepsilon(1)$. Also, since $g$ is strictly convex, it is easy to show that for any $e<\varepsilon(1), 1>g^{\prime}(e)$.

The slopes of the two indifference curves $V_{M}(w, e)=A$ and $V_{K}(w, e)=A^{\prime}$ are given by

$$
\begin{aligned}
\left.\frac{\partial w}{\partial e}\right|_{V_{M}=A} & =\frac{1-w}{e}=\frac{(1-w)\left(1-\alpha_{K}\right)}{e\left(1-\alpha_{K}\right)}>0 \\
\left.\frac{\partial w}{\partial e}\right|_{V_{K}=A^{\prime}} & =\frac{1-w\left(1-\alpha_{K}\right)-\alpha_{K} g^{\prime}(e)}{e\left(1-\alpha_{K}\right)} \\
& =\frac{(1-w)\left(1-\alpha_{K}\right)+\alpha_{K}\left(1-g^{\prime}(e)\right)}{e\left(1-\alpha_{K}\right)}
\end{aligned}
$$

Then, $\left.\frac{\partial w}{\partial e}\right|_{V_{M}=A} \leq\left.\frac{\partial w}{\partial e}\right|_{V_{K}=A^{\prime}}$ for any $w \in[0,1]$ and $e \in[0, \varepsilon(1)]$. Moreover, the inequality holds strictly for all $e<\varepsilon(1)$.

Our model, much like most signaling models, suffers from the multiple equilibria problem. More succinctly, the equilibrium concept does not help us pin down a particular outcome over others. Rather, the equilibrium outcomes that are characterized by $(P 1),(P 2)$, and $(B)$ are numerous and have different characteristics. For example, under our assumptions so far we can have both separating equilibria where the worker correctly deduces the employer's motive, and pooling equilibria in which the two types can not be distinguished.

The multiplicity of equilibria, however, can be overcome by introducing "reasonable" restrictions on off-equilibrium beliefs for the workers. The restrictions we impose on the worker's beliefs are based on the refinement concept of "intuitive criterion", introduced by Cho and Kreps [7].

Given an equilibrium profile $\left(w^{*}(\cdot), e^{*}(\cdot), \mu^{*}(\cdot)\right)$, where $\mu^{*}(\cdot)=\left(\mu_{M}^{*}(\cdot), \mu_{K}^{*}(\cdot)\right)$, let $V_{i}^{*}=V_{i}\left(w^{*}\left(\alpha_{i}\right), e^{*}\left(w^{*}\right)\right)$ denote the equilibrium payoff of a type $i$ employer. We say that wage $w$ is equilibrium dominated for employer $i=M, K$ if

$$
V_{i}^{*}>\max _{e \in \varepsilon(w)} V_{i}(w, e) .
$$

Let $\Theta^{*}(w) \subset\{M, K\}$ denote the types of employers for which condition (2.15) fails to hold. In other words, $i \in \Theta^{*}(w)$ only if $w$ is not equilibrium dominated, or if $V_{i}^{*} \leq \max _{e \in \varepsilon(w)} V_{i}(w, e)$. The next condition summarizes our refinement concept.

(R) A PBE $\left(w^{*}(\cdot), e^{*}(\cdot), \mu^{*}(\cdot)\right)$ has reasonable beliefs if for all $w$ with $\Theta^{*}(w) \neq \varnothing, \mu_{i}^{*}(w)>0$ is true only if $i \in \Theta^{*}(w)$. 
As in most models that utilize the intuitive criterion and its close variants, the restrictions on off-equilibrium beliefs significantly reduce the number of possible equilibria. For example, condition $(R)$ ensures that if $\Theta^{*}(w)=i$ for some offer $w$, then the degenerate belief that the employer is type $i, \mu_{i}(w)=1$, is reasonable, since $j \notin \Theta^{*}(w)$ implies that $\mu_{j}(w)=0$. Our next result characterizes the PBE that are supported by reasonable beliefs.

Proposition 2.7. There is a unique separating PBE outcome $\left(w^{*}(\cdot), e^{*}(\cdot)\right)$ with equilibrium beliefs $\mu^{*}(\cdot)$ that satisfy $(R)$.

Proof. Let $\left(w^{*}, e^{*}(\cdot), \mu^{*}(\cdot)\right)$ any pooling equilibrium profile that satisfies $(P 1)$, $(P 2)$, and $(B)$ and let $V_{K}^{*}$ and $V_{M}^{*}$ be the corresponding payoffs for each type of employer.

We now show that a pooling equilibrium cannot be supported by beliefs that satisfy $(R)$. In order to prove this, it is sufficient to show that there exists some wage $w^{\prime}$ which is feasible with belief $\mu_{K}\left(w^{\prime}\right)=1$, i.e. $\pi\left(w^{\prime}, \mathcal{E}\left(w^{\prime}, \beta \alpha_{K}\right)\right) \geq 0$, such that

$$
\begin{aligned}
V_{K}^{*} & \leq V_{K}\left(w^{\prime}, \mathcal{E}\left(w^{\prime}, \beta \alpha_{K}\right)\right), \\
V_{M}^{*} & >V_{M}\left(w^{\prime}, \mathcal{E}\left(w^{\prime}, \beta \alpha_{K}\right)\right) .
\end{aligned}
$$

The first inequality requires that $w^{\prime}$ makes $K$ at least as well off as in the pooling outcome. The second inequality ensures that $M$ strictly prefers the pooling outcome to $\left(w^{\prime}, \mathcal{E}\left(w^{\prime}, \beta \alpha_{K}\right)\right)$. If beliefs are reasonable, these two inequalities ensure that by offering $w^{\prime}$, a kind employer can (and would weakly prefer to) signal her intentions to the worker, i.e. $\mu_{K}\left(w^{\prime}\right)=1$ since $\Theta^{*}\left(w^{\prime}\right)=\{K\}$. Consequently, the two inequalities (2.16-2.17) refute that a pooling equilibrium satisfies $(R)$.

First, note that the equilibrium payoff of a materialist must be strictly positive, or that $V_{M}^{*}>0$. To see this, suppose otherwise, or that $V_{M}^{*} \leq 0$. Our assumption regarding the profitability of the project ensures that there exists some $w^{\prime \prime}$ such that $\pi\left(w^{\prime \prime}, \mathcal{E}\left(w^{\prime \prime}, 0\right)\right)>0$. Since $\mathcal{E}$ and $\pi$ are increasing in their second arguments, then a type $M$ employer would be better off by offering $w^{\prime \prime}$ - no matter what the employer believes - contradicting condition $(P 2)$ for a materialist at the pooling equilibrium.

We now prove that there exists some $w^{\prime}$ that satisfies both conditions $(2.16)$ and (2.17). Using the argument in the proof of Lemma 2.6, we can verify that the slopes of the indifference curves that intersect at the pooling equilibrium, 
$V_{M}(w, e)=V_{M}^{*}$ and $V_{K}(w, e)=V_{K}^{*}$, are ordered, such that

$$
\left.\frac{\partial w}{\partial e}\right|_{V_{K}=V_{K}^{*}}>\left.\frac{\partial w}{\partial e}\right|_{V_{M}=V_{M}^{*}}>0,
$$

for any $w \in[0,1)$ and $e \in[0, \mathcal{E}(1)) .{ }^{10}$

Let us define $w^{0}$ as the greatest wage that yields a materialist employer payoff of $V_{M}^{*}$ when the worker believes that the employer is kind, i.e. $w^{0}=$ $\max \left\{w \in[0,1]: V_{M}\left(w, \mathcal{E}\left(w, \beta \alpha_{K}\right)\right)=V_{M}^{*}\right\} .{ }^{11}$ It is easy to show that $w^{0}>w^{*}$. Note that $w^{0}<1$ since $V_{M}^{*}>0$. Then, equation (2.18) and Lemma 2.6 imply that $V_{K}\left(w^{0}, \mathcal{E}\left(w^{0}, \beta \alpha_{K}\right)\right)>V_{K}^{*}$. Since $\mathcal{E}$ is continuous, increasing in its second argument, and $V_{M}^{*}>0$, there exists some feasible wage $w^{\prime}>w^{0}$ which satisfies both conditions (2.16) and (2.17).

Now let $\left(w^{*}(\cdot), e^{*}(\cdot), \mu^{*}(\cdot)\right)$ be any separating equilibrium profile that satisfies $(P 1),(P 2)$, and $(B)$. First, note at a separating equilibrium the indifference curve for a materialist employer and the best response $\mathcal{E}(\cdot, 0)$ have to be tangent to each other at point $\left(w^{*}(0), e^{*}\left(w^{*}(0)\right)\right)$. To see this, note that $(P 1)$ and $(B)$ imply that $\left(w^{*}(0), e^{*}\left(w^{*}(0)\right)\right)$ has to be a point on the best response function for a materialist, $\mathcal{E}(\cdot, 0)$. Assume now that the materialist employer's indifference curve that passes through $\left(w^{*}(0), e^{*}\left(w^{*}(0)\right)\right)$ is not tangent to $\mathcal{E}(\cdot, 0)$. But this would imply that there exists some $w^{\prime}$ and a corresponding best response effort $e^{\prime}=\mathcal{E}\left(w^{\prime}, 0\right)$ such that $V_{M}\left(w^{\prime}, e^{\prime}\right)>V_{M}^{*}$, contradicting $(P 2)$.

Given that a materialist worker's indifference curve has to be tangent to $\mathcal{E}(\cdot, 0)$, we now turn to the equilibrium choice of a kind employer. Let

$$
\Phi_{K}^{*} \equiv\left\{w \in[0,1]: \Theta^{*}(w)=K\right\}
$$

determine the set of wages that a type $K$ employer may use to signal her type. We know from our discussion above that $\Phi_{K}^{*}$ is non-empty. Then, offering a wage that exceeds lower bound of $\Phi_{K}^{*}$, i.e. $w>w_{l}=\min _{w} \Phi_{K}^{*}$, violates $(P 2)$ and thus can not be an equilibrium wage. This means that $\left(w_{K}^{*}, \mathcal{E}\left(w_{K}^{*}, \beta \alpha_{K}\right)\right)$ must be on the indifference curve that is defined by $V_{M}(w, e)=V_{M}^{*}$. Lastly, the equilibrium

\footnotetext{
${ }^{10}$ Since $r>0, w=1$ can not be a feasible offer and is not considered.

${ }^{11} \mathrm{It}$ is easy to show that there is at least one wage $w$ such that $V_{M}\left(w, \mathcal{E}\left(w, \beta \alpha_{K}\right)\right)=V_{M}^{*}$. To see this, note that assuming otherwise would imply that there exists no point on the graph of $\mathcal{E}\left(w, \beta \alpha_{K}\right)$ that a materialist employer prefers to the pooling equilibrium. This is impossible since the pooling equilibrium is a point on the graph of $\mathcal{E}\left(w, \beta p_{K} \alpha_{K}\right)$, which implies less effort for any given wage.
} 
wage $w_{K}^{*}=w_{l}$ is feasible since, by using the same argument we have used above for a pooling equilibrium, one can show that $V_{M}^{*}>0$ has to be true at a separating equilibrium.

Our previous result shows that wage signals successfully reveal the motives of an employer in the simple setting we have identified. In other words, a materialist employer is unable to extract any loyalty from the worker. This result goes against the popular belief that wages and bonuses are effective only in providing pecuniary incentives. $^{12}$

The uniqueness result, however, depends crucially on the economic context surrounding the labor market interaction. We next illustrate with an example that if the employer is unable to secure positive profits by being recognized as a materialist, then pooling outcomes may not be ruled out by the reasonable beliefs described by $(R)$. Moreover, in such a case it is also possible that the project may not be implemented at all.

Example 2.8. Let $g(e)=e^{2}, r=0.2, \beta=0.9, \alpha_{K}=0.8$, and $p_{K}=0.5$. Then, the best response function of the worker is given by

$$
\mathcal{E}(w, b)=\frac{1}{2}(w+(1-b) w)
$$

where $b=\beta \alpha_{K} \mu_{K}$. We depict four possible outcomes in Figure 2.3. Panel a) depicts the case where an equilibrium belief profile $\mu_{K}^{*}$ where neither type finds it feasible to implement the project. Note, in particular, that $\mu_{K}^{*} \leq p_{K}$ for all $w$. Panel b) depicts the separating PBE outcome in which the type $K$ employer chooses a wage that successfully signals her type. The PBE action profile is where the two curves $V_{M}^{*}$ and $V_{K}^{*}$ intersect. The type $M$ employer does not implement the project. Panels c) and d) depict two pooling PBE outcomes.

\section{Local Interaction}

Most labor interactions have a local aspect, in that some employers are better known then others. In this section, we consider an extreme case in which the

\footnotetext{
${ }^{12}$ One may critize the above finding on the grounds that the model is too simplistic and does not take account of intricate details of labor relations. For example, employers are usually not as liquidity constrained as we have assumed. Most labor contracts include a fixed wage as well as a bonus, dependent on output level, past profits, etc. However, as shown in the appendix, relaxing the liquidity constraints to allow the employer to offer a fixed wage scheme does not affect our qualitative results.
} 


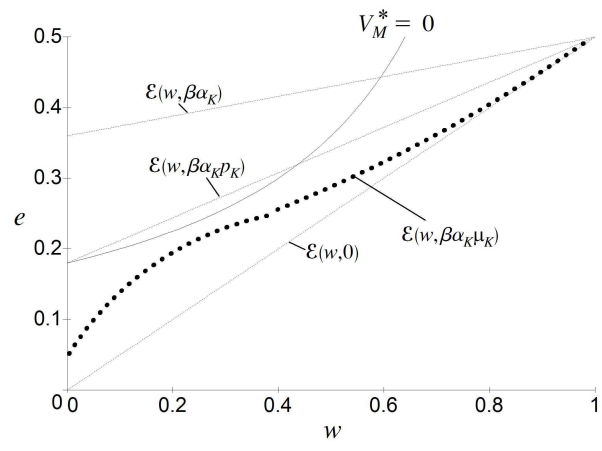

a)

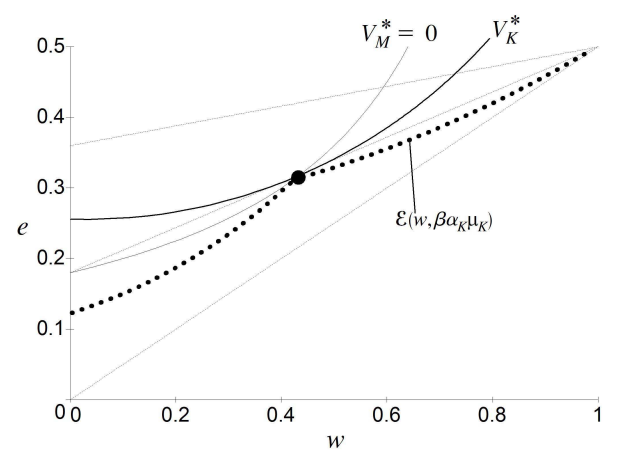

c)

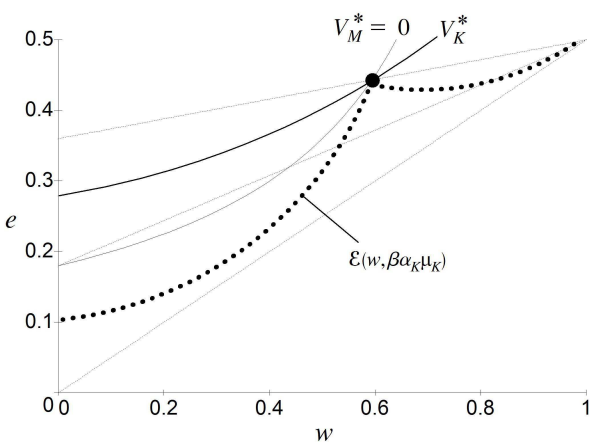

b)

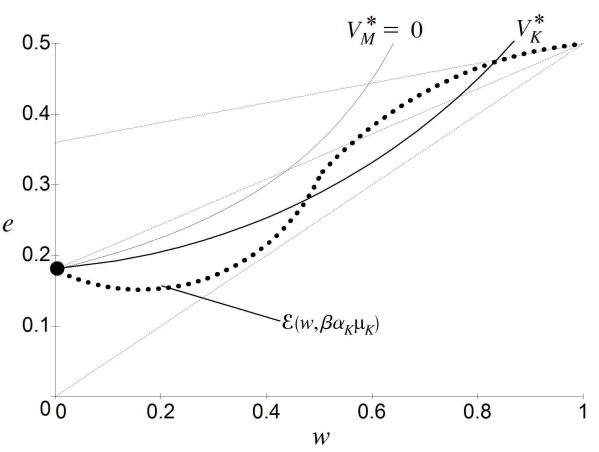

d)

Figure 2.3: The four outcomes for Example 2.8. 
worker has perfect information regarding the motive of one employer but is uncertain about the motive of the other. It is quite easy to see that if the local employer is a materialist, the worker will choose to work with another local employer who is known to be kind. We rule out such a case since local employers that do not care about their workers are probably eliminated in the long run.

Suppose then that the first (local) employer is observed to be kind. The motive of the second (outsider) employer, however, is unobserved. Since the worker can perfectly observe the motive of the first employer, in this section the vector $\mu=\left(\mu_{K}, \mu_{M}\right)$ refers to beliefs regarding the second employer's motives. Let $r_{1}, r_{2}>0$ and $w_{1}, w_{2} \geq 0$ denote the capital costs and offers of the two employers. Notice that if $r_{2}=r_{1}$, then the set of feasible wages that can be offered by the two employer are identical if the worker believes that the second employer is kind, or if $\mu_{K}=1$. Also, let us assume that if the worker is indifferent between the offers of the two employers then she will always choose to work for the local employer. ${ }^{13}$

Our model in this section can easily be interpreted as a model of loyalty, in which the worker chooses either to continue working for a local firm or to start working for the second (outsider) firm. As in the previous section, we only consider cases where both employers can make positive profits even if the worker believes that they are materialistic:

$$
\pi\left(w, \mathcal{E}(w, 0) \mid r_{i}\right)>0
$$

for some $w$ and for both employers $i=1,2$.

The next result shows that unless the second employer's capital cost is sufficiently smaller than some threshold level, the first employer will be able to persuade the worker to work for her and secure a strictly positive profit.

Lemma 3.1. Given the worker's belief, $\mu_{K} \in[0,1]$, there exists some strictly increasing threshold, $\Omega\left(\mu_{K}\right) \leq r_{1}$, such that if $r_{2} \geq \Omega\left(\mu_{K}\right)$ then the local employer will be able to persuade the worker to work for her by offering the wage $w_{1}^{*}>0$. The threshold is equivalent to the rent of local employer if worker believes that the outsider employer is kind with certainty, such that $\Omega(1)=r_{1}$.

Proof. The value for threshold $\Omega$ can be found by the solution to the following system of equations for the five variables $Y=\left[w_{1}, e_{1}, w_{2}, e_{2}, \Omega\right]$ :

\footnotetext{
${ }^{13}$ This assumption is simply to retain the simplicity of our model and does not alter any of our results.
} 


$$
\begin{aligned}
w_{1}-g^{\prime}\left(e_{1}\right)+\beta \alpha_{K}\left(1-w_{1}\right) & =0 \\
w_{2}-g^{\prime}\left(e_{2}\right)+\beta \alpha_{K} \mu_{K}\left(1-w_{2}\right) & =0 \\
\left(1-w_{2}\right) e_{2}-\Omega & =0 \\
\left(1-w_{1}\right) e_{1}-r_{1} & =0 \\
U\left(w, e, \beta \alpha_{K} \mid r_{1}\right)-U\left(w, e, \beta \alpha_{K} \mu_{K} \mid r_{2}\right) & =0 .
\end{aligned}
$$

The first two equations (3.1-3.2) determine the worker's best responses, $e_{1}$ and $e_{2}$, to wages $w_{1}$ and $w_{2}$. Note that these two equations imply that $e_{2} \leq e_{1}$. Equation (3.3) defines the threshold as a function of the wage offered by the second employer and the worker's best response to that wage. Equation (3.4) sets the greatest feasible wage that can be offered by employer 1 to compete with the wage offered by employer 2. Lastly, equation (3.5) relates the wages and efforts that make the worker indifferent between working for the first or the second employer. These equations ensure that if $r_{2} \geq \Omega\left(\mu_{K}\right)$ then the outsider employer may offer some feasible wage that will persuade the worker.

In order to see that $\Omega$ is strictly increasing, we implicitly differentiate equations (3.1-3.5) to get

$$
\begin{aligned}
& {\left[\begin{array}{l}
\frac{\partial w_{1}}{\partial \mu_{K}} \\
\frac{\partial e_{1}}{\partial \mu_{K}} \\
\frac{\partial w_{2}}{\partial \mu_{K}} \\
\frac{\partial e_{2}}{\partial \mu_{K}} \\
\frac{\partial \Omega}{\partial \mu_{K}}
\end{array}\right]=-\left[\begin{array}{lllll}
1-\beta \alpha_{K} & -g^{\prime \prime}\left(e_{1}\right) & 0 & 0 & 0 \\
0 & 0 & 1-\beta \alpha_{K} \mu_{K} & -g^{\prime \prime}\left(e_{2}\right) & 0 \\
0 & 0 & -e_{2} & -w_{2} & -1 \\
-e_{1} & -w_{1} & 0 & 0 & 0 \\
e_{1}\left(1-\beta \alpha_{K}\right) & 0 & -e_{2}\left(1-\beta \alpha_{K} \mu_{K}\right) & 0 & 0
\end{array}\right]^{-1}} \\
& \times\left[\begin{array}{l}
0 \\
\beta \alpha_{K}\left(1-w_{2}\right) \\
0 \\
0 \\
-\beta \alpha_{K}\left(1-w_{2}\right) e_{2}
\end{array}\right] .
\end{aligned}
$$

The above calculation gives us how the threshold responds to $\mu_{K}$ :

$$
\frac{\partial \Omega}{\partial \mu_{K}}=\beta \alpha_{K}\left(1-w_{2}\right) \frac{e_{2}}{1-\beta \alpha_{K} \mu_{K}}>0
$$

If $\mu_{K}=1$, equations (3.1) and (3.2) define identical response functions. Then, equations (3.3) and (3.4) also need to be identical, such that $\Omega(1)=r_{1}$. Since $\Omega$ is increasing, then $\Omega\left(\mu_{K}\right)<r_{1}$ for all $\mu_{K}<1$. 
The previous result exhibits a simple consequence of loyalty. Unless the second employer offers a sufficiently larger wage, the worker will choose the first player that she knows is kind. Therefore, the worker not only works harder but also chooses the first employer even if her outside option is slightly better.

Corollary 3.2. When $r_{2} \geq \Omega(1)$, the outsider employer can not offer a wage large enough to employ the worker. When $r_{2}<\Omega(0)$, there is a unique separating outcome that satisfies $(R)$ in which the worker will work for the outsider employer no matter what her type is.

Proof. By the definition of threshold $\Omega$, when $r_{2} \geq \Omega(1)$, the outsider employer can not offer a feasible wage to hire the worker. ${ }^{14}$ When $r_{2}<\Omega(0)$, the outsider employer can make a feasible wage offer which is strictly better than the local employer's offer by revealing her type, no matter what her type is. The rest of the proof for this case is identical to the proof of Proposition 2.7.

Our next result shows another interesting aspect of our model. The model has a pooling equilibrium with reasonable beliefs when a materialist (outsider) employer is unable to hire the worker by revealing her type while a kind (outsider) employer is able to hire the worker. Note that these results are similar in spirit to those that were illustrated in Example 2.8.

Proposition 3.3. Assume that $r_{2} \in[\Omega(0), \Omega(1))$. There are multiple equilibria, including pooling equilibria, that satisfy $(R)$. In a separating equilibrium, a materialist (outsider) employer has no wage to persuade the worker while a kind (outsider) employer obtains zero profits. The outcomes can further be characterized as follows:

i). When $r_{2} \in\left[\Omega(0), \Omega\left(p_{K}\right)\right]$, the worker will work for the local employer only at a separating equilibrium and only if the outsider employer is type $M$.

ii). When $r_{2} \in\left(\Omega\left(p_{K}\right), \Omega(1)\right)$, the worker will work for the outsider employer only at a separating equilibrium and only if she is type $K$.

Proof. When $\Omega(0) \leq r_{2}<\Omega(1)$, the kind employer can offer a feasible which will persuade the worker to work for her. However, within the same range, a materialist

\footnotetext{
${ }^{14}$ Note our assumption that the worker will always choose the local employer if she is indifferent between the offers of local and outsider employers.
} 
employer has no feasible wage which will persuade the worker by revealing her type. In fact, the only separating equilibrium that satisfies $(P 2)$ must be yield both types zero profits. It is easy to see why the materialist obtains zero profits in a separating equilibrium: She simply has no feasible wage to persuade the worker to work for her instead of the local employer. As for a kind worker, let us assume instead that she may obtain positive profit by offering some feasible wage $w_{K}$, such that $\pi\left(w_{K}, \mathcal{E}\left(w_{K}, \beta \alpha_{K}\right)\right)>0$. But then, the materialist worker has an incentive to offer $w_{K}$ instead of revealing her type by offering some wage $w_{M} \neq w_{K}$. This would violate $(P 2)$ and $(B)$ and therefore $\pi\left(w_{K}^{*}, \mathcal{E}\left(w_{K}^{*}, \beta \alpha_{K}\right)\right)=0$ has to hold at a separating equilibrium.

The previous paragraph also shows that there exists no feasible wage that satisfies condition 2.17 in the proof of Proposition 2.7. The simple reason is that in a separating equilibrium a materialist employer always obtains zero profits since she is never chosen by the worker. Then, any wage $w^{\prime}$ that satisfies condition 2.17 is infeasible by definition, since the condition requires

$$
V_{M}\left(w^{\prime}, \mathcal{E}\left(w^{\prime}, \beta \alpha_{K}\right)\right)<V_{M}^{*}=0 .
$$

Therefore, $(R)$ does not help us weed out any pooling equilibria.

With these in mind, when $r_{2} \in\left[\Omega(0), \Omega\left(p_{K}\right)\right]$, both types of employers can feasibly offer a wage to hire a worker at a pooling equilibrium. The worker will choose to work for the local employer only at a separating equilibrium and when the employer is a materialist. Finally, when $r_{2} \in\left(\Omega\left(p_{K}\right), \Omega(1)\right]$ there exists no feasible pooling equilibrium wage that makes the worker choose the outsider employer. The outsider employer can offer a feasible wage to hire the worker only at a separating equilibrium and only if she is kind.

\section{Conclusion}

The main concern of this paper has been whether motives could be signalled through different wage offers. We first observed that with a single employer signals were used to their fullest extent, separating the two types of employers. The results in the previous section however showed us that with two employers and a single worker, if the worker had an affinity to a kind employer, then unless the other employer offered a sufficiently high wage, the worker will always choose the kind employer. As we noted in the beginning of the paper, if appearing to be selfish reduces an employer's ability to attract workers, then the only equilibrium 
that is supported by reasonable beliefs may reduce the employer's ability to signal their types.

The results obtained in the last section may also explain why loyalty perceptions have been declining for big companies. As technology advances, capital costs decline, enabling some employers to offer high wages that break the pull of loyalty for some workers. The problem is that a kind employer may not be able to signal her type properly, since appearing to be selfish results in inferior net earnings. Therefore, all employers offer a high (pooling) wage, which evidently reduces the flow of information.

\section{Appendix}

In this appendix, we assume that there is a large number $N$ of identical workers to be employed by a single employer. We assume that the number of workers is sufficiently large such that the employer may pool her entire production risk by hiring all the workers. In this setting, an employer may choose to offer a compensation scheme $\omega(y)=w_{0}+w y$, with a strictly positive fixed payment, $w_{0}>0$. Note however that in our framework the fixed payment $w_{0}$ cannot be interepreted as an insurance, since both the worker and the employer are riskneutral. Instead, $w_{0}$ is just another tool that can be used to signal the employer's motive. Intuitively, the fixed payment is a much more attractive signalling device than the conditional payment $w$ since it does not alter the worker's incentives.

As there are a large number of workers, the employer's total revenue from hiring all $N$ workers is given by $N e$. The employer's feasibility constraints are now defined as

$$
0 \leq w \leq 1 \text { and } 0 \leq w_{0} \leq e(1-w)
$$

where the last inequality follows from the requirement that total payments must be less than total revenues, or that $N\left(w_{0}+w e\right) \leq N e$.

The expected private payoffs of the worker and the employer can be given by

$$
\begin{aligned}
& u(\omega, e)=e w+w_{0}-g(e), \\
& \pi(\omega, e)=e(1-w)-w_{0}-r,
\end{aligned}
$$

where $r$ again denotes the production unit's resale value. As before, the two agents may develop mutual care, which is captured by the extended payoff functions:

$$
\begin{aligned}
U(\omega, e, b) & =u(\omega, e)+b \pi(\omega, e), \\
V_{i}(\omega, e) & =\pi(\omega, e)+\alpha_{i} u(\omega, e),
\end{aligned}
$$


The worker's care for the employer, $b=\beta E_{\mu}[\alpha]$, is again based on her reaction coefficient, $\beta \in[0,1]$, and her anticipation of the employer's altruism coefficient, $E_{\mu}[\alpha]=\mu_{K} \alpha_{K}$.

When the employer's motives are observable, it is easy to show that the worker's best response is not dependent on the fixed payment, $w_{0}$. Therefore, $\mathcal{E}(w, b)$ is defined as above in equation (2.5).

Let us start with the the employer's decision problem when efforts are observed. In this case, the employer's optimization is

$$
\begin{aligned}
& \max _{w, w_{0}} V_{i}\left(\omega, \mathcal{E}\left(w, b_{i}\right)\right) \\
& \text { s.t. i. } u\left(\omega, \mathcal{E}\left(w, b_{i}\right)\right) \geq 0, \quad \text { ii. } w_{0} \geq 0 \text {, iii. } w \geq 0 \text {, } \\
& \text { iv. } w_{0} \leq \mathcal{E}\left(w, b_{i}\right)(1-w) \text {, v. } w \leq 1 \text {, }
\end{aligned}
$$

where $b_{i}=\beta \mu_{i} \alpha_{i}$.

Lemma 5.1. When motives are fully observable, the employer will offer no fixed payment, $w_{0}=0$.

Proof. The Lagrangian for the problem in (5.3) can be written as

$$
\begin{aligned}
\mathcal{L}_{i}= & \mathcal{E}\left(w, b_{i}\right)(1-w)-w_{0}-r \\
& +\left(\alpha_{i}+\gamma_{i}^{1}\right)\left(\mathcal{E}\left(w, b_{i}\right) w+w_{0}-g\left(\mathcal{E}\left(w, b_{i}\right)\right)\right) \\
& +\gamma_{i}^{2} w_{0}+\gamma_{i}^{3} w-\gamma_{i}^{4}\left(w_{0}-\mathcal{E}\left(w, b_{i}\right)(1-w)\right)-\gamma^{5}(w-1) \\
= & \mathcal{E}\left(w, b_{i}\right)\left(1-w\left(1-\alpha_{i}-\gamma_{i}^{1}+\gamma_{i}^{4}\right)+\gamma_{i}^{4}\right)+\gamma_{i}^{3} w-\gamma^{5}(w-1) \\
& -w_{0}\left(1-\alpha_{i}-\gamma_{i}^{1}-\gamma_{i}^{2}+\gamma_{i}^{4}\right)-r-\left(\alpha_{i}+\gamma_{i}^{1}\right) g\left(\mathcal{E}\left(w, b_{i}\right)\right),
\end{aligned}
$$

where $\gamma_{i} \geq 0$ denote the Lagrangian multipliers for type $i$ employer. Then, the optimal choices are characterized by

$$
\begin{aligned}
\frac{\partial \mathcal{L}_{i}}{\partial w}= & \frac{\partial \mathcal{E}}{\partial w} \cdot\left(1-w\left(1-\alpha_{i}-\gamma_{i}^{1}+\gamma_{i}^{4}\right)+\gamma_{i}^{4}-\left(\alpha_{i}+\gamma_{i}^{1}\right) g^{\prime}\right) \\
& -\left(1-\alpha_{i}-\gamma_{i}^{1}+\gamma_{i}^{4}\right) \mathcal{E}+\gamma_{i}^{3}-\gamma_{i}^{5} \\
= & 0, \\
\frac{\partial \mathcal{L}_{i}}{\partial w_{0}}= & -\left(1-\alpha_{i}-\gamma_{i}^{1}-\gamma_{i}^{2}+\gamma_{i}^{4}\right)=0 .
\end{aligned}
$$


Note that the first order condition for $w_{0}$ in (5.6) implies that if $w_{0}>0$, such that $\gamma_{i}^{2}=0$, then $1-\alpha_{i}-\gamma_{i}^{1}+\gamma_{i}^{4}=0$. Substituting into $(5.4-5.5)$ gives

$$
\frac{\partial \mathcal{E}}{\partial w} \cdot\left(1+\gamma_{i}^{4}\right)\left(1-g^{\prime}\right)+\gamma_{i}^{3}-\gamma_{i}^{5}=0
$$

From the first order condition of the worker in (2.7), we have

$$
g^{\prime}=w\left(1-\beta \alpha_{i}\right)+\beta \alpha_{i} \leq 1 .
$$

Let us assume that $w=1$ such that $g^{\prime}=1$. But then $w_{0}=0$ has to hold due to the feasibility constraint $w_{0} \leq(1-w) \mathcal{E}=0$, which contradicts $w_{0}>0$. Also, $g^{\prime}=1$ if $\beta \alpha_{i}=1$. Assuming $\beta \alpha_{i}<1, w<1$ can not be an optimal choice according to (5.7), since this implies $\gamma_{i}^{5}=0$ and $1-g^{\prime}>0$. Therefore, $w_{0}=0$ must hold except when $\beta \alpha_{i}=1$.

The result should not come as a surprise. We assumed from the start that the worker and the employer are both risk neutral. Therefore, there is no reason for the employer to insure the worker.

When the employer's motives are not observable, however, the employer may be interested in providing some fixed wage to signal her type to the worker. Note that the fixed wage does not provide any direct incentives, or that the worker's best response function is not dependent on $w_{0}$. Before continuing to provide our seperation result, we first show that the employer's indifference curves satisfy the "modified" single-crossing property when both $w_{0}$ and $w$ can be variables.

Lemma 5.2. For any given $\bar{w}, \bar{m} \in[0,1], V_{i}\left(\left(\bar{w}, w_{0}\right), e\right)$ and $V_{i}((w, \bar{m}), e)$ satisfy single-crossing for $w, w_{0} \in[0,1]$ and $e \in[0, \mathcal{E}(1)]$.

Proof. To show that $V_{i}\left(\left(\bar{w}, w_{0}\right), e\right)$ is single-crossing is elementary since $\mathcal{E}$ does not depend on $w_{0}$. To show that $V_{i}((w, \bar{m}), e)$ is single-crossing, we can use the identical line of arguments provided in the proof of Lemma 2.6, which will not be repeated here.

As before, the previous result ensures that there exist some feasible compensation offers that are prefered only by a benevolent employer. The next result summarizes our findings.

Proposition 5.3. There is a unique (separating) PBE outcome $\left(\omega^{*}(\cdot), e^{*}(\cdot)\right)$ with equilibrium beliefs $\mu^{*}(\cdot)$ that satisfy $(R)$. In this unique equilibrium, $w_{0}^{*}\left(\alpha_{M}\right)=0$. Moreover, a benevolent (type $K$ ) employer will choose to use $w_{0}$ solely for signaling, such that $w_{i}^{*}=\arg \max _{w} V_{i}(\omega, \mathcal{E}(w, b))$ and $w_{0}=\left(1-w_{K}^{*}\right) \mathcal{E}\left(w_{K}^{*}, \beta \alpha_{K}\right)-$ $\left(1-w_{M}^{*}\right) \mathcal{E}\left(w_{M}^{*}, 0\right)$. 
Proof. Again, it is easy to show that $(R)$ helps us eliminate all but the "best" separating equilibrium outcome. The proof is almost identical to the proof in Proposition 2.7 and will not be repeated.

In order to signal her benevolent motive, a type $K$ employer's offer $\omega=\left(w, w_{0}\right)$ has to make a type $M$ employer worse-off than her actual offer, $\omega_{M}^{*}=\left(w_{M}^{*}, 0\right)$. Thus,

$$
V_{M}\left(\omega, \mathcal{E}\left(w, \beta \alpha_{K}\right)\right)>V_{M}\left(\omega_{M}^{*}, \mathcal{E}\left(w_{M}^{*}, 0\right)\right)
$$

or equivalently,

$$
w_{0}>(1-w) \mathcal{E}\left(w, \beta \alpha_{K}\right)-\left(1-w_{M}^{*}\right) \mathcal{E}\left(w_{M}^{*}, 0\right) .
$$

Then, a type $K$ employer chooses

$$
\begin{aligned}
\max _{w, w_{0}} & V_{K}\left(\omega, \mathcal{E}\left(w, \beta \alpha_{K}\right)\right) \\
\text { s.t. } & \text { i. } u\left(\omega, \mathcal{E}\left(w, b_{i}\right)\right) \geq 0, \text { ii. } w_{0} \geq 0, \\
& \text { iii. } w \geq 0, \text { iv. } w_{0} \leq(1-w) \mathcal{E}\left(w, \beta \alpha_{K}\right), \text { v. } w \leq 1, \\
& \text { vi. } w_{0} \geq(1-w) \mathcal{E}\left(w, \beta \alpha_{K}\right)-\left(1-w_{M}^{*}\right) \mathcal{E}\left(w_{M}^{*}, 0\right) .
\end{aligned}
$$

The Lagrangian can be written as

$$
\begin{aligned}
\mathcal{L}= & (1-w) \mathcal{E}\left(w, \beta \alpha_{K}\right)-w_{0}-r+\left(\alpha_{K}+\gamma_{1}\right)\left(w \mathcal{E}\left(w, \beta \alpha_{K}\right)+w_{0}-g\left[\mathcal{E}\left(w, \beta \alpha_{K}\right)\right]\right) \\
& +\gamma_{2} w_{0}+\gamma_{3} w-\gamma_{4}\left(w_{0}-(1-w) \mathcal{E}\left(w, \beta \alpha_{K}\right)\right)+\gamma_{5}(w-1) \\
& +\gamma_{6}\left(w_{0}-(1-w) \mathcal{E}\left(w, \beta \alpha_{K}\right)+\left(1-w_{M}^{*}\right) \mathcal{E}\left(w_{M}^{*}, 0\right)\right) .
\end{aligned}
$$

The first order conditions are then given by

$$
\begin{aligned}
\frac{\partial \mathcal{L}}{\partial w}= & \frac{\partial \mathcal{E}}{\partial w} \cdot\left(1-\gamma_{6}+\gamma_{4}-w\left(1-\alpha_{K}-\gamma_{1}+\gamma_{4}-\gamma_{6}\right)-\left(\alpha_{i}+\gamma_{i}^{1}\right) g^{\prime}\right) \\
& -\mathcal{E}\left(1-\alpha_{K}-\gamma_{1}+\gamma_{4}-\gamma_{6}\right)+\gamma_{3}-\gamma_{5} \\
= & 0 \\
\frac{\partial \mathcal{L}}{\partial w_{0}}= & -\left(1-\alpha_{K}-\gamma_{1}-\gamma_{2}+\gamma_{4}-\gamma_{6}\right)=0
\end{aligned}
$$

It is easy to show that $0<w<1$, such that $\gamma_{3}=\gamma_{5}=0$. Using condition (5.9), we then have

$$
1+\gamma_{4}-\gamma_{6}=\gamma_{1}+\gamma_{2}+\alpha_{K}
$$

We can rewrite the first-order condition for $w$ given in (5.8) as

$$
\frac{\partial \mathcal{L}}{\partial w}=\frac{\partial \mathcal{E}}{\partial w} \cdot\left(\gamma_{1}+\gamma_{2}+\alpha_{K}-\gamma_{2} w-\left(\alpha_{K}+\gamma_{1}\right) g^{\prime}\right)-\left(1-\alpha_{K}\right) \mathcal{E}=0
$$


This is exactly the same first-order condition in lemma 5.1, corresponding to the employer's optimal wage choice when her motives are observed. Therefore, $w_{M}^{*}=w_{M}^{o}$ and $w_{K}^{*}=w_{K}^{o}$.

\section{References}

[1] Akerlof, G. A., (1982) "Labor Contracts as Partial Gift Exchange," Quarterly Journal of Economics, 97, 543 - 569.

[2] Bernheim, B.D. and S. Severinov (2003) "Bequests as Signals: An Explanation for the Equal Division Puzzle," Journal of Political Economy 111, 733 -64 .

[3] Bolton, G. and A. Ockenfels (2000), "ERC: A Theory of Equity, Reciprocity and Competition," American Economic Review 90, 166 - 93.

[4] Camerer, C. (1998), "Gifts as Economic Signals and Social Symbols," American Journal of Sociology 94, S180 - S214.

[5] Camerer, C. (2001), Behavioral Game Theory: Experiments on Strategic Interaction, Princeton: Princeton University Press.

[6] Charness, G. and E. Haruvy (2002), "Altruism, Equity, and Reciprocity in a Gift-Exchange Experiment: an Encompassing Approach," Games and Economic Behavior 40, 203 - 231.

[7] Cho, I. and D. Kreps, (1987) "Signaling Games and Stable Equilibria," Quarterly Journal of Economics, 102, 179 - 221.

[8] Falk, A. and U. Fischbacher, (2000) "A Theory of Reciprocity," University of Zurich Working Paper, No. 6.

[9] Fehr, E. and S. Gächter, (2000) "Fairness and Retaliation: The Economics of Reciprocity," Journal of Economic Perspectives 14, 159 - 181.

[10] Fehr, E. and K.M. Schmidt (1999), "A Theory of Fairness, Competition, and Cooperation," Quarterly Journal of Economics 114, 817 - 68.

[11] Geanakoplos, J., D. Pearce, and E. Stacchetti (1989), "Psychological Games and Sequential Rationality," Games and Economic Behavior 1, 60 - 79. 
[12] Güth, W., (1995) "On Ultimatom Bargaining Experiments - A Personal Review," Journal of Economic Behavior and Organization 27, 329 - 344.

[13] Ledyard, J. (1995) "Public Goods: A Survey of Experimental Research," in J. Kagel and A. Roth (eds.) Handbook of Experimental Economics, Prineton: Princeton University Press.

[14] Levine, D. K., (1998) "Modeling Altruism and Spitefulness in Experiments," Review of Economic Dynamics, 1, 593 - 622.

[15] Prasnikar, V. and A. Roth (1992), "Considerations of Fairness and Strategy: Experimental Data from Sequential Games," Quarterly Journal of Economics $79,355-84$.

[16] Rabin, M., (1993) "Incorporating Fariness into Game Theory and Economics," American Economic Review 83, 1281 - 1302.

[17] Roth, A., (1995) "Bargaining Experiments," in J. Kagel and A. Roth (eds.) Handbook of Experimental Economics, Prineton: Princeton University Press.

[18] Sethi, Rajiv and E. Somanathan (2003), "Understanding Reciprocity," Journal of Economic Behavior and Organization 50, $1-27$.

[19] Sobel, J. (2005) "Interdependent Preferences and Reciprocity," Journal of Economic Literature 43, 392 - 436. 